
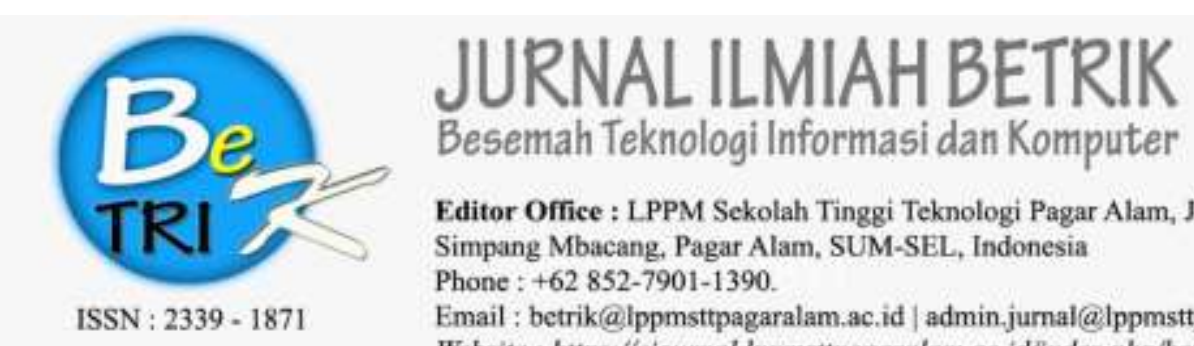

Editor Office : LPPM Sekolah Tinggi Teknologi Pagar Alam, Jn. Masik Siagim No. 75 Simpang Mbacang, Pagar Alam, SUM-SEL, Indonesia Phone : +62 852-7901-1390.

Email : betrik@lppmsttpagaralam.ac.id | admin.jurnal@lppmsttpagaralam.ac.id Website : https://ejournal.lppmsitpagaralam.ac.id/index.php/betrik/index

\title{
APLIKASI PENGAJUAN BEASISWA BERBASIS WEB PADA KANTOR WALIKOTA BAGIAN ADMINISTRASI KESEJAHTERAAN RAKYAT (KESRA) DUMAI
}

\author{
Eli Tri Sulis Setia Rini ${ }^{1}$, Nurhadi ${ }^{2}$ \\ ${ }^{1}$ Mahasiswa Teknik Informatika, STMIK Dumai ${ }^{2}$ Dosen Teknik Informatika, STMIK Dumai \\ ${ }^{1}$ Jalan Utama Karya No. 04 Kel Bukit Batrem Kec. Dumai Timur Kota Dumai \\ 1e-mail : elitrs_stmik@gmail.com \\ 2e-mail : flinkdumai@gmail.com
}

\begin{abstract}
Abstrak : Penelitian pada Kantor Walikota Bagian Administrasi Kesejahteraan Rakyat (KESRA) Dumai, dimana permasalahan yang dijadikan dasar yaitu pengajuan beasiswa, pengajuan beasiswa yang dilakukan masih secara manual. Sehingga dalam pengajuan beasiswa banyak mahasiswa mengalami kendala, karena mahasiswa tersebut ada yang studi di luar kota. Sehingga dalam pengajuan beasiswa dikatakan kurang efektif dan efesien. Oleh karena itu, dirancang sebuah aplikasi pengajuan beasiswa berbasis web pada kantor walikota bagian administrasi kesejahteraan rakyat (KESRA) Dumai. Manfaat terbesar dari perancangan aplikasi ini adalah agar dapat mempermudah mahasiswa dalam mengajukan beasiswa. Dimana pengembangan aplikasi ini menggunakan bahasa pemograman PHP.
\end{abstract}

Kata kunci : Beasiswa, Dumai, Administrasi, Mahasiswa, PHP

Abstract: Research on Mayor Office of Public Welfare Administration Department (KESRA) Dumai, where the problem is the basis of the scholarship application, scholarship application is still done manually. So in the scholarship application many students experience obstacles, because the students are studying outside the city. So in the scholarship application is said to be less effective and efficient. Therefore, it is designed a web-based scholarship application application at the mayor's office of public welfare administration (KESRA) Dumai. The greatest benefit of designing this application is to make it easier for students to apply for scholarships. Where the development of this application using PHP programming language.

Keywords: Scholarship, Dumai, Administration, Student, PHP

\section{PENDAhULUAN}

\section{Bagian Administrasi Kesejahteraan}

Rakyat (KESRA) merupakan salah satu lembaga pemerintahan yang berhubungan dengan masyarakat dan di kenal luas di masyarakat Kota Dumai.

Salah satu bantuan yang di berikan

oleh Bagian Administrasi KESRA yaitu 


\section{Eli Tri Sulis Setia Rini \& Nurhadi}

beasiswa, setiap tahunnya beasiswa yang diberikan kepada mahasiswa meningkat yang terdiri dari beasiswa prestasi, beasiswa kurang mampu dan beasiswa tugas akhir. Dalam pengajuan beasiswa banyak mahasiswa mengalami kendala, karena mahasiswa tersebut ada yang studi di luar kota. Sehingga dalam pengajuan beasiswa dikatakan kurang efektif dan efesien, jika mahasiswa yang studi diluar kota harus datang langsung ke Kantor Walikota Bagian Administrasi KESRA. Sehingga mahasiswa yang memiliki Indeks Prestasi Kumulatif (IPK) tinggi tidak dapat mengajukan beasiswa.

Pada saaat ini Bagian Administrasi KESRA memberikan informasi beasiswa pada mahasiswa masih manual, sehingga mengakibatkan keterlambatan dalam memperoleh informasi.

Berdasarkan uraian di atas, maka perlu dirancang sebuah aplikasi yang berbasis web untuk mempermudah mahasiswa melakukan pengajuan beasiswa tanpa harus datang langsung ke Kantor Walikota Dumai. Mahasiswa cukup mengajukan beasiswa dengan cara online. Karena itu akan dirancang aplikasi dengan judul "Aplikasi Pengajuan Beasiswa Berbasis Web Pada Kantor Walikota Bagian Administrasi Kesejahteraan Rakyat (Kesra) Dumai ".

Berdasarkan latar belakang penelitian di atas maka dapat di identifikasi beberapa permasalahan yaitu Mahasiswa yang studi di luar kota tidak dapat mengajukan beasiswa secara langsung, Registrasi pengajuan beasiswa kurang efektif dan efisien dan Membutuhkan waktu untuk datang langsung ke Kantor Walikota Bagian Administrasi KESRA.

Berdasarkan latar belakang diatas dapat dirumuskan permasalahan yang akan diselesaikan yaitu bagaimana merancang dan membuat sebuah aplikasi pengajuan beasiswa berbasis online di Administrasi KESRA Dumai dengan menggunakan sebuah aplikasi berbasis web agar dapat membantu pengajuan beasiswa yang efektif dan efisien.

Adapun tujuan dari penelitian ini adalah Membuat perancangan aplikasi pengajuan beasiswa berbasis web pada Kantor Walikota bagian Administrasi KESRA Dumai Dan kegunaan dari penelitian ini adalah Mempermudah Mahasiswa mengajukan beasiswa secara Online, Mempermudah penyaluran dana beasiswa bagi mahasiswa, Membantu Bagian Administrasi KESRA dalam hal penyaluran dana beasiswa dan Hasil penelitian ini akan dapat menambah wawasan dan pengetahuan khusus dalam bidang Manajemen Informatika dan Ilmu Komputer yang ada hubungannya dengan masalah-masalah aplikasi online.

\section{METODO PENELITIAN}

\subsection{Metode Penelitian}

Adapun mendapatkan suatu hasil dari masalah diperlukan data dan informasi yang objektif. Adapun pengumpulan data yang 
Eli Tri Sulis Setia Rini \& Nurhadi

digunakan dalam penelitian ini adalah sebagai berikut :

a) Tempat dan waktu penelitian

Penelitian ini dilakukan pada Kantor Walikota Bagian Administrasi KESRA Dumai, yang dilakukan pada jam kerja. Adapun yang menjadi objek dalam penelitian adalah staf bagian beasiswa yang ada di Administrasi KESRA Dumai.

b) Jenis Penelitian

Untuk mendapatkan suatu hasil dari masalah yang akan di teliti, diperlukan data dan informasi yang objektif, tugas penelitian di lakukan pada studi kasus di kantor Walikota bagian Administrasi KESRA Dumai. Jenis penelitian deskriptif dengan metode sebagai berikut:

a. Penelitian pustaka (Library Research)

Selain memperoleh data dan informasi yang dibutuhkan dari kantor Walikota bagian Administrasi KESRA Dumai, penelitian juga didukung dengan referensi buku-buku dan referensi dari internet dan lainnya yang sesuai dengan penelitian yang dibuat, agar data yang didapat bisa dijadikan acuan untuk menyelesaikan permasalahan dan dapat diketahui dengan benar.

b. Penelitian Lapangan ( Field Research) Yakni melakukan penelitian langsung pada kantor Walikota bagian Administrasi KESRA Dumai dengan pihak-pihak yang terkait dengan permasalahan yang dibahas dalam penelitian ini, untuk mendapatkan datadata yang diperlukan serta untuk mengetahui dengan rinci permasalah yang dihadapi selama ini.

c. Penelitian Laboratorium

\section{( Laboratory Research)}

Penelitian lain yang juga dilakuakan adalah penelitian laboratorium yang merupakan sarana dalam menunjang penyelesaian pembuatan program aplikasi dan pengetikan.

c) Teknik analisa data

1) Teknik wawancara

Dalam pengumpulan data, dilakukan teknik wawancara dengan mengajukan berbagai pertanyaan kepada staf KESRA bagian beasiswa di Walikota bagian Administrasi KESRA Dumai tentang permasalahan data dan kendala yang dihadapi selama ini dalam hal mengolah pengajuan beasiswa.

2) Observasi

Metode observasi yakni melakukan penelitian secara langsung ke kantor Walikota bagian Administrasi KESRA Dumai.

\subsection{Definisi Aplikasi}

Menurut Hengky W. Pramana (2010), Aplikasi adalah suatu unit perangkat lunak yang dibuat untuk melayani kebutuhan akan beberapa aktifitas seperti sistem perniagaan, game pelayanan masyarakat, periklanan, atau semua proses yang hampir dilakukan manusia. 


\section{Eli Tri Sulis Setia Rini \& Nurhadi}

Menurut Jogiyanto (2008:h.9), Aplikasi adalah program yang telah jadi dan siap untuk digunakan atau program yang dibuat sendiri.

\subsection{Beasiswa}

Beasiswa adalah pemberian berupa bantuan yang diberikan kepada perorangan yang bertujuan untuk digunakan demi keberlangsungan pendidikan yang ditempuh.

\subsection{Pengertian Website}

Website adalah kumpulan halaman web yang diletakan dalam satu tempat/site/situs. Jadi, di dalam website terdapat halamanhalaman $w e b$, beserta file-file pendukungnya yang diletakan dalam satu tempat yang diidentifikasi melalui nama domain (domain name) dan alamat ip ( IP address). (Tim EMS, 2012: h.1)

\subsection{Internet (Interconnected Networking)}

Internet adalah sebuah sistem teknologi komunikasi yang bisa menghubungkan antar satu komputer dengan komputer lainnya sehingga menjadi sebuah jaringan, jaringan ini mencakup seluruh dunia.

\subsection{Aliran Sistem Informasi Berjalan}

Berdasarkan hasil penelitian yang dilakukan pada Kantor Walikota Bagian Administrasi Kesejahteraan Rakyat Dumai, maka dapat diuraikan system yang sedang berjalan saat mengadakan pengajuan beasiswa adalah sebagai berikut.
Mahasiswa yang akan mengajukan beasiswa harus menyerahkan persyaratan atau proposal pengajuan beasiswa terlebih dahulu ke Kantor Walikota Bagian Administrasi Kesejahteraan Rakyat Dumai dengan memberikan persyaratan atau proposal pengajuan beasiswa. Setelah menyerahkan persyaratan atau proposal pengajuan beasiswa akan menunggu informasi untuk penerimaan dan penandatangan amprah. Selanjutnya mahasiswa menunggu informasi pencairan dana beasiswa ke rekening masing-masing.

Untuk lebih jelasnya mengenai pengajuan beasiswa yang sedang berjalan di Bagian Administrasi Kesejahteraan Rakyat Dumai, maka akan dijelaskan dalam aliran system informasi pengajuan beasiswa yang sedang berjalan pada Bagian Administrasi Kesejahteraan Rakyat Dumai, dapat dilihat pada gambar 5 dibawah ini.

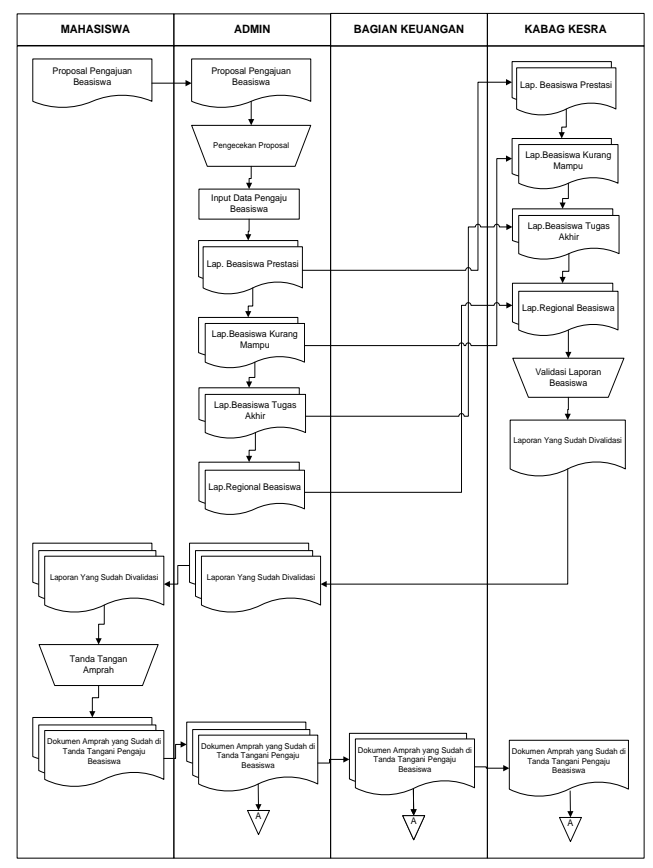

Gambar 1. Aliran Sistem Informasi Berjalan 


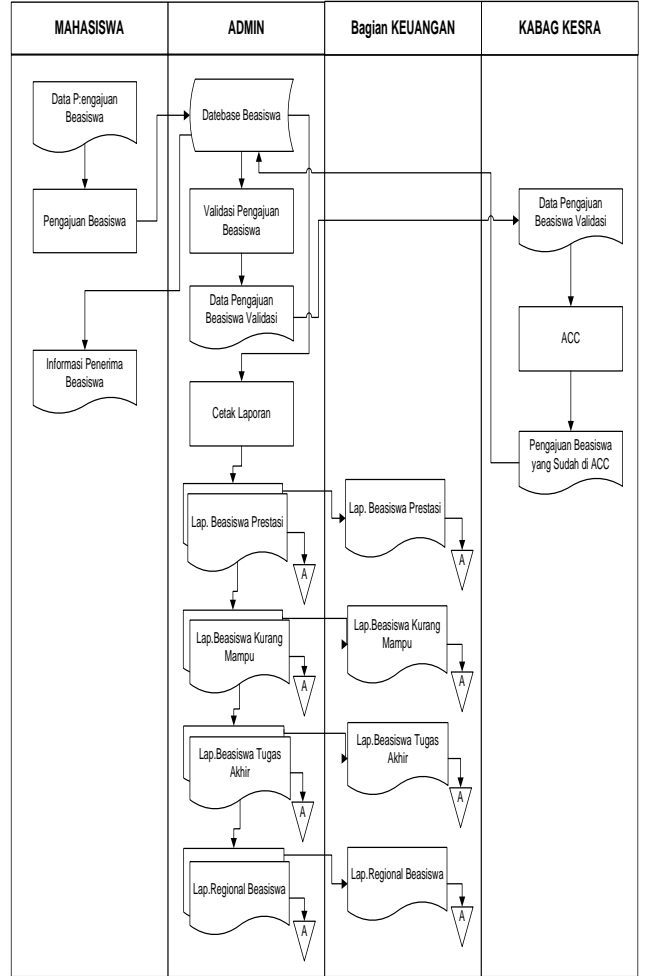

Gambar 2. Aliran Sistem Informasi Baru

\subsubsection{Contex Diagram}

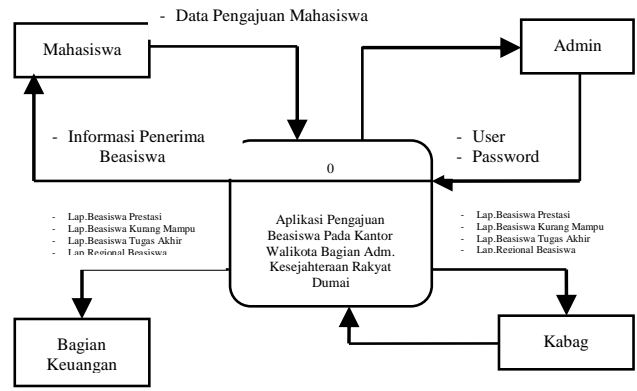

Gambar 3. Contex Diagram

\subsubsection{Data Flow Diagram}

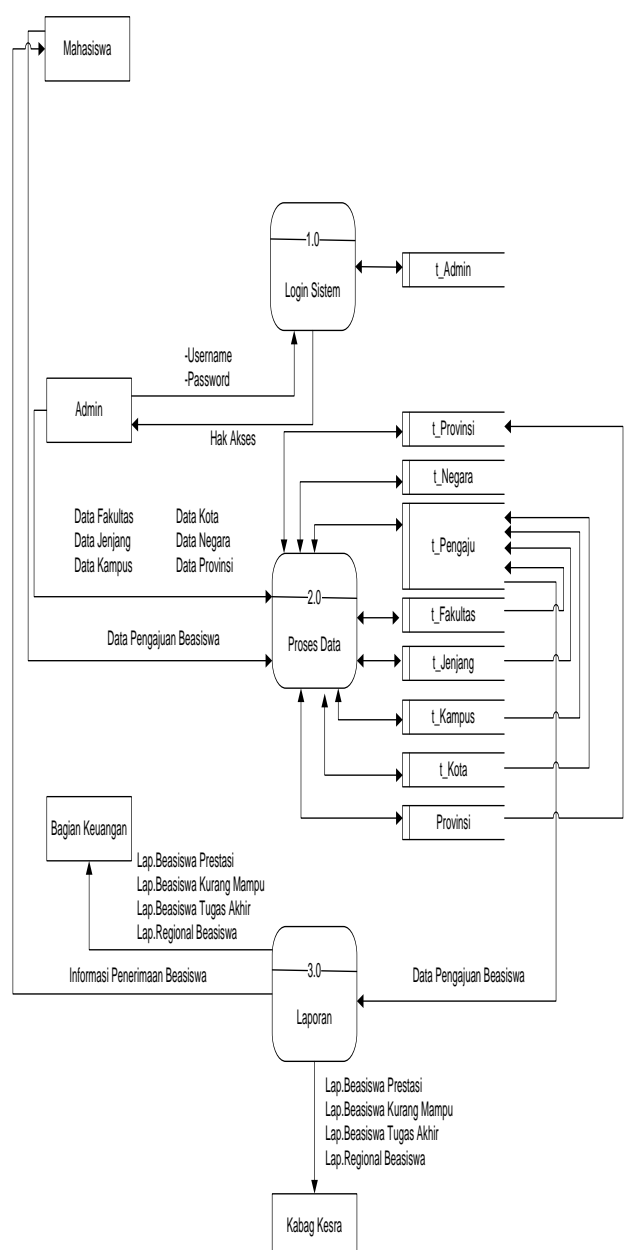

Gambar 4. Data Flow Diagram

\subsubsection{Perancangan Output}

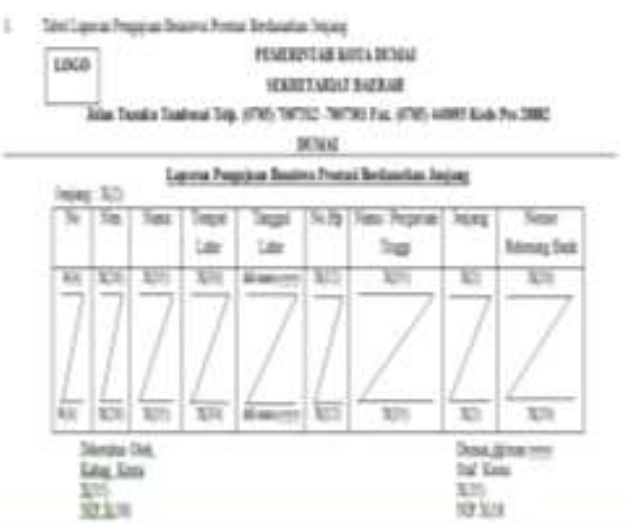

Gambar 5. Perancangan Output Pengajuan 


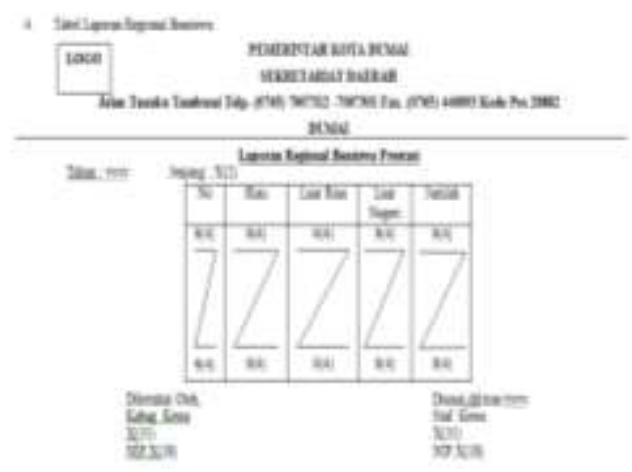

Gambar 6. Perancangan Laporan Beasiswa Regional

\subsubsection{Perancangan File}

Dalam membuat suatu program diperlukan adanya file yang saling berinteraksi satu sama lainnya. File yang digunakan pada aplikasi ini adalah sebagai berikut:

Tabel 1. Tabel Mahasiswa

\begin{tabular}{|c|c|c|c|}
\hline \$o & Fied & 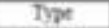 & Ketriecle \\
\hline 1 & latra & $\ln (15)$ & Jendina Bewivina \\
\hline 2 & Mg & Ventar(s) & Sathar KTF \\
\hline 3 & Pumbia benim & Douks & Finfift beaing \\
\hline
\end{tabular}

Tabel 2. Tabel Jenjang

\begin{tabular}{|c|c|c|c|}
\hline No & Field & Type & Keterangen \\
\hline 1 & 1d_jenjumg & $\operatorname{Int}(10)$ & Identras Jenjung \\
\hline 2 & Jenians & Varchar(2) & Jeniasig \\
\hline 3 & Aletif & Emoum(yx) & Akthf \\
\hline 4 & 10 Kempus & $\ln (5)$ & Ideutios Kampes \\
\hline
\end{tabular}

Tabel 3. Tabel Kampus

\begin{tabular}{|c|c|c|c|}
\hline No & Fineld & Type & Keferangan \\
\hline 1 & Id_kingu & $\ln (3)$ & Doenatas Kantipu \\
\hline 7 & Nama kampu & Vactar(3) & Nama Kampus \\
\hline 3 & Aktif & Enire(y,n) & Aletif \\
\hline
\end{tabular}

\section{HASIL DAN PEMBAHASAN}

\subsection{Tampilan Login}

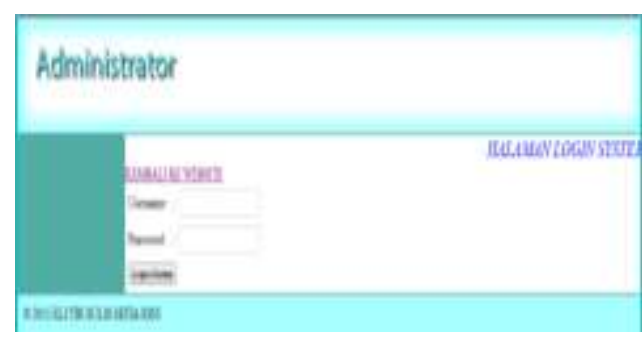

Gambar 7. Tampilan Login

\subsection{Tampilan Home}

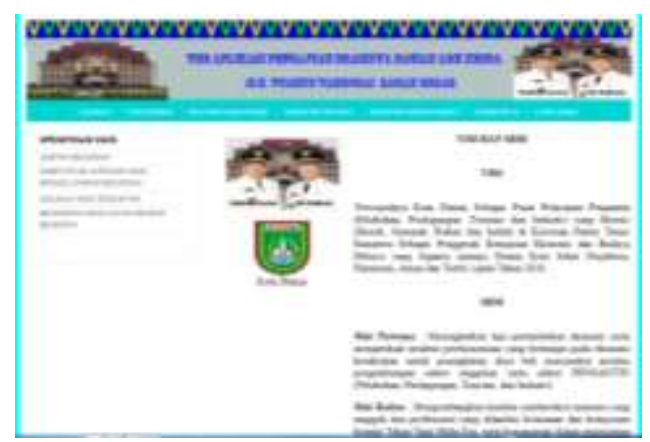

Gambar 8. Tampilan Home

\subsection{Tampilan Input Pengajuan Beasiswa}

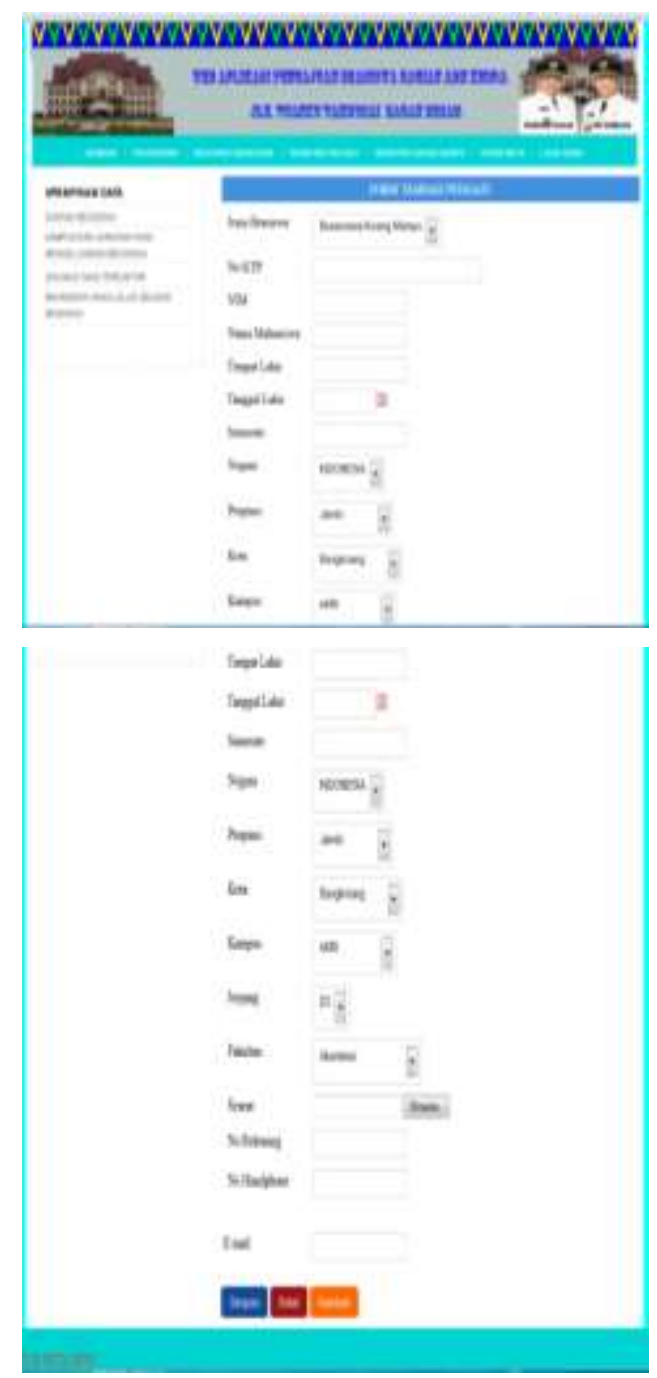

Gambar 9. Input Pengajuan Beasiswa 


\subsection{Tampilan Input Data Negara}

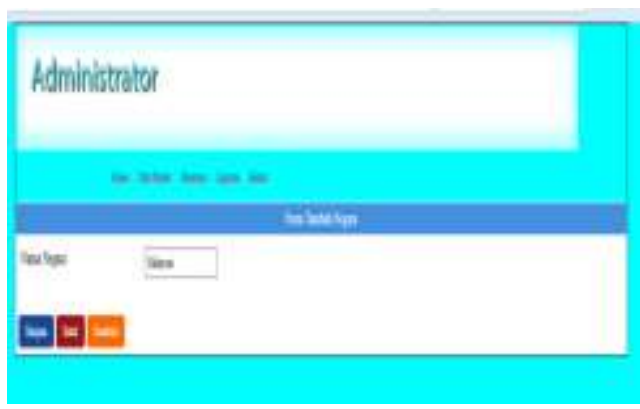

Gambar 10. Tampilan Input Data Negara

\subsection{Tampilan Input Data Provinsi}

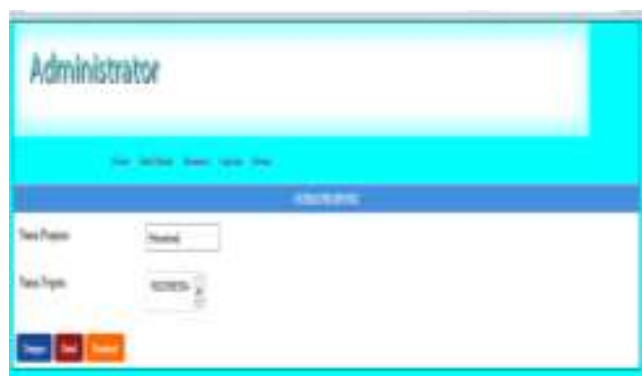

Gambar 11. Tampilan Input Data Provinsi

\subsection{Tampilan Input Data Kota}

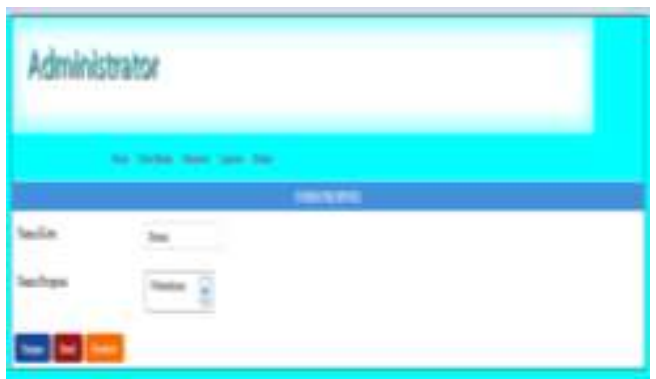

Gambar 12. Tampilan Input Data Kota

\subsection{Tampilan Input Data Kampus}

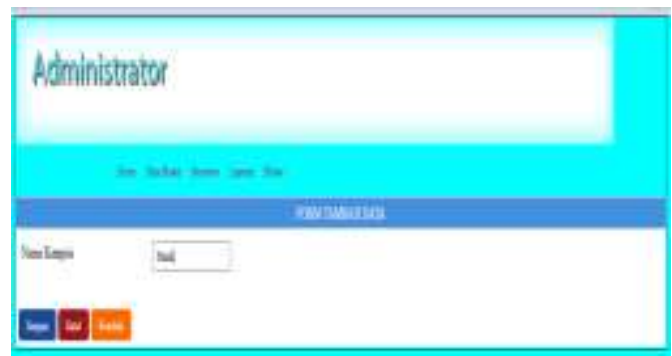

Gambar 13. Tampilan Input Data Kampus

\subsection{Laporan Pengajuan Beasiswa Pertasi} Berdasarkan Jenjang

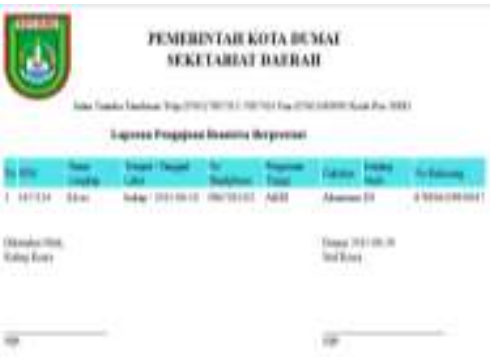

Gambar 14. Laporan Pengajuan Beasiswa Prestasi Berdasarkan Jenjang

\section{SIMPULAN}

Berdasarkan penguraian yang penulis paparkan, tentunya dapat diambil kesimpulan sebagai berikut :

a. Dengan menggunakan aplikasi pengajuan beasiswa berbasis online di Administrasi KESRA Dumai dengan menggunakan sebuah aplikasi berbasis web agar dapat membantu pengajuan beasiswa yang efektif dan efisien.

b. Dengan menggunakan aplikasi pengajuan beasiswa berbasis online dapat mempermudah mahasiswa mengajukan beasiswa sehingga efektif dan efisien.

c. Dengan menggunakan aplikasi yang berbasis web untuk mempermudah mahasiswa melakukan pengajuan beasiswa tanpa harus datang langsung ke Kantor Walikota Dumai. 


\section{DAFTAR PUSTAKA}

Agus Saputra dkk. (2013). Menyelesaikan Website 12 Juta secara Profesional. PT. Elex Media Komputindo. Jakarta.

Bunafit Nugroho. (2013). Dasar Pemrograman Web PHP-MySQL dengan Dreamweaver. Gava Media. Yogyakarta.

Diar Puji Oktavian. (2013). Membuat Website Powerfull Menggunakan PHP. MediaKom. Yogyakarta.

Hanif Al Fatta. (2007). Analisis \& Perancangan Sistem Informasi. CV. Andi Offset. Yogyakarta.

Indrajani. (2011). Perancangan Basis Data All in 1. PT. Elex Media Komputindo. Jakarta.

Jogiyanto. (2009). Sistem Teknologi Informasi. CV. Andi Offset. Yogyakarta.

Jusuf Soewadji, MA (2012). Pengantar Metodologi Penelitian. CV. Mitra Wacana Media. Jakarta.

Kusrini. (2007). Strategi Perancangan dan Pengolahan Basis Data. CV. Andi Offset. Yogyakarta.

Lukmanul Hakim. (2014). Rahasia Inti Master PHP \& MySQL. CV. Lokomedia. Yogyakarta.

Simarmata, J. (2007). Perancangan Basis Data. CV. Andi Offset. Yogyakarta.

Tata Sutabri. (2012). Konsep Sistem Informasi. CV. Andi Offset. Yogyakarta.

Tim Ems. (2009). Cara Mudah Menjadi Web Master. PT. Elex Media Komputindo. Jakarta.

Wahana Komputer. (2010) Panduan Belajar MySQL Database Server. Mediakita. Jakarta.

Yudi Priyadi, M.T. (2013). Kolaborasi SQL \& ERD Dalam Implementasi Database. CV. Andi Offset. Bandung. 